\title{
Low Gestational Age Is the Strongest Predictor for Severe Retinopathy of Prematurity and Adverse Outcomes at Two-Year Follow-Up in a Low Incidence Setting
}

\author{
Stefano Nobile ${ }^{1}$ Linda Bordignon ${ }^{1} \quad$ Anna Maria Peretti ${ }^{1} \quad$ Virgilio Paolo Carnielli $^{1}$ \\ ${ }^{1}$ Division of Neonatology, Department of Mother and Child Health, \\ Salesi Children's Hospital, Ancona, Italy \\ J Child Sci 2017;7:e106-e109. \\ Address for correspondence Stefano Nobile, MD, PhD, Division of \\ Neonatology, Department of Mother and Child Health, Salesi \\ Children's Hospital, via F. Corridoni 11, Ancona 60123, Italy \\ (e-mail: stefano.nobile@ospedaliriuniti.marche.it).
}

\begin{abstract}
We aimed to determine the risk factors for type 1 ROP and outcomes at 2 years of corrected age among preterms born $<30$ weeks of gestational age (GA) in a low-incidence setting. $A$ cohort study with 447 infants was conducted. Those who underwent laser therapy for type 1 ROP were compared with controls by univariate and multivariate analysis. Neurological development was assessed by Bayley scales. Using univariate analysis, gestational age,

Keywords

- preterm infant

- retinopathy of prematurity

- risk factors

- gestational age

- laser therapy sepsis, necrotizing enterocolitis, and insulin administration were found to be associated with type 1 ROP. Only GA remained significant with logistic regression. Infants with type 1 ROP had worse visual and neurodevelopmental outcomes at 2 years. Predictors of impaired neurodevelopment were type 1 ROP, surfactant administration, and bronchopulmonary dysplasia. Low GA was found to be a strong predictor of type 1 ROP, which was associated (along with surfactant administration and bronchopulmonary dysplasia) with worse neurological development.
\end{abstract}

\section{Introduction}

Retinopathy of prematurity (ROP) is a major cause of childhood blindness worldwide. ${ }^{1}$ Despite advanced care in neonatology, approximately $16 \%$ of extremely low gestational age neonates suffer from advanced ROP ( $\geq$ stage 3 ) and $12 \%$ undergo ROP treatment. ${ }^{2}$ The pathogenesis of ROP is multifactorial, and several risk factors have so far been identified. Previous studies in larger cohorts with higher ROP prevalence have shown that low gestational age (GA), low birth weight (BW), and oxygen use are the most important risk factors for ROP; however, other associated factors have been recently described (i.e., days of ventilation, sepsis, hyperglycemia, blood transfusions, severe hypotension, and impaired postnatal weight gain). ${ }^{3-9}$

Even if the incidence of blindness among preterm infants suffering from ROP has decreased over time owing to more effective therapies, the occurrence of severe (type 1) ROP requiring treatment is still associated with significant longterm visual impairment, such as myopia and strabismus. ${ }^{10}$

The objectives of this work were (1) to determine risk factors for type 1 ROP (stage $\geq 3$ or plus disease) requiring laser therapy among preterm infants admitted at our lowincidence, regional level III NICU, and (2) to find out if infants treated for severe ROP had adverse visual and neurodevelopmental outcomes.

\section{Patients and Methods}

This study was a retrospective evaluation of prospectively collected data from all infants born $<30$ weeks of GA who were admitted to our regional NICU from January 2004 to December 2013. Infants were examined by the same pediatric ophthalmology service following ROP international classification throughout the study period..$^{10}$ All infants were screened by indirect ophthalmoscopy starting on day 30 (GA at birth received

May 1, 2017

accepted after revision

July 3, 2017
DOI https://doi.org/

$10.1055 / \mathrm{s}-0037-1604476$. ISSN 2474-5871.
Copyright @ 2017 Georg Thieme Verlag KG Stuttgart · New York

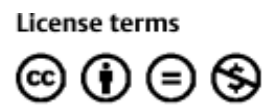


$<27$ weeks) or day 15 (GA at birth between 27 and 32 weeks) and strictly followed up. Severe (type 1) ROP was defined as stage $3,4,5$, or plus disease. ${ }^{11}$

We reviewed patients' data collected in our database and ophthalmology surgical notes from 2004 to 2013. Neurodevelopmental outcome was assessed at 2 years of corrected age by means of Bayley scales (third edition) by a skilled physiotherapist and a neonatologist. ${ }^{12}$ Composite motor and cognitive scores were calculated for each infant, and the occurrence of visual impairment was assessed as reported by ophthalmology follow-up visits. The local Institutional Review Board approved the study.

Sepsis was defined as a positive blood culture or suggestive clinical and laboratory findings leading to treatment with antibiotics for at least 72 hours. The diagnosis of patent ductus arteriosus (PDA) was assessed by heart ultrasound performed by skilled neonatologists. Bronchopulmonary dysplasia (BPD) was defined according to the physiologic definition. ${ }^{13}$

Demographics and clinical characteristics of patients who underwent laser therapy for type 1 ROP were compared with controls (no ROP or ROP stage 1-2 without indication for treatment) by means of univariate analysis: $t$-test for normally distributed numerical data, Mann-Whitney test for skewed numerical data, and chi-squared analysis for categorical variables. A $p$-value $<0.05$ was considered significant. A logistic regression analysis was then performed including the aforementioned variables to find predictors of laser therapy for severe ROP. Another logistic regression analysis was performed to find out predictors of neurodevelopmental impairment (cognitive score $<85$, motor score $<70$ ). SPSS (version 19.0; IBM, Armonk, New York, United States) was used to perform statistics. Data were presented as percentages for categorical data, mean, and standard deviation for normally distributed numerical data and as median and interquartile range (IQR) for skewed data.

\section{Results}

Five hundred fifty-eight infants were born during the study period; 73 died before the scheduled ROP examination, 20 had major malformations, and 18 had incomplete data. The study population consisted of 447 infants; 356 out of 447 (79.6\%) had follow-up data (Bayley test was assessed in 237 patients).

Type 1 ROP occurred in 10 patients out of 447 (2.2\%) who underwent laser treatment. These patients were compared with those who did not suffer from type 1 ROP (stage 1 ROP, $n=107$; stage 2 ROP, $n=126$; no ROP, $n=204$ ). The results are shown in -Table $\mathbf{1}$.

Table 1 Comparison of clinical outcomes between infants with severe ROP and infants with mild/no ROP using univariate analysis

\begin{tabular}{|c|c|c|c|}
\hline & $\begin{array}{l}\text { Type } 1 \text { ROP } \\
n=10\end{array}$ & $\begin{array}{l}\text { Mild/no ROP } \\
n=437\end{array}$ & $p$-Value \\
\hline Birth weight $(\mathrm{g})$, median (IQR) & $818(741-878)$ & $982(800-1,202)$ & 0.090 \\
\hline Gestational age (days), median (IQR) & $180(177-186)$ & $196(187-203)$ & 0.000 \\
\hline Male gender, $n(\%)$ & $4(40)$ & $232(53)$ & 0.526 \\
\hline SGA, $n(\%)$ & $1(10)$ & $26(6)$ & 0.454 \\
\hline Preeclampsia, $n(\%)$ & $1(10)$ & $109(25)$ & 0.463 \\
\hline Antenatal steroids, $n(\%)$ & $8(80)$ & $389(89)$ & 0.301 \\
\hline Intubation in the delivery room, $n(\%)$ & $6(60)$ & $192(44)$ & 0.351 \\
\hline Surfactant administration, $n(\%)$ & $9(90)$ & $284(65)$ & 0.176 \\
\hline $\mathrm{FiO}_{2}$ on day 7 of life, median (IQR) & $0.21(0.21-0.28)$ & $0.21(0.21-0.23)$ & 0.690 \\
\hline $\mathrm{FiO}_{2}$ on day 14 of life, median (IQR) & $0.28(0.23-0.32)$ & $0.21(0.21-0.25)$ & 0.061 \\
\hline Patent ductus arteriosus, $n(\%)$ & $9(90)$ & $288(66)$ & 0.176 \\
\hline Early-onset sepsis, $n(\%)$ & $2(20)$ & $26(6)$ & 0.133 \\
\hline Late-onset sepsis (no. of episodes), median (IQR) & $1(0-3)$ & $0(0-1)$ & 0.003 \\
\hline Necrotizing enterocolitis, $n$ (\%) & $2(20)$ & $13(3)$ & 0.046 \\
\hline Bronchopulmonary dysplasia, $n(\%)$ & $4(40)$ & $114(26)$ & 0.297 \\
\hline $\begin{array}{l}\text { Prevalent human milk feeding } \\
\text { (>66\% of the total amount during hospital stay), } n(\%)\end{array}$ & $3(30)$ & $214(49)$ & 0.341 \\
\hline Dopamine therapy, $n(\%)$ & $5(50)$ & $118(27)$ & 0.143 \\
\hline Weight gain at week 6 of life $(\mathrm{g} / \mathrm{kg} / \mathrm{d})$, mean (SD) & $23.1(14.8)$ & $17.3(6.0)$ & 0.182 \\
\hline Blood transfusions per patient, median (IQR) & $7(2-10)$ & $1(0-3)$ & 0.111 \\
\hline Insulin requirement, $n(\%)$ & $3(30)$ & $31(7)$ & 0.033 \\
\hline
\end{tabular}

Abbreviations: Fi, fraction of inspired oxygen; IQR, interquartile range; ROP, retinopathy of prematurity; SD, standard deviation; SGA, small for gestational age. 
Table 2 Comparison of clinical outcomes between infants with type 1 ROP and infants with mild/no ROP using univariate analysis

\begin{tabular}{|l|l|l|l|}
\hline & $\begin{array}{l}\text { Type 1 ROP } \\
\boldsymbol{n}=\mathbf{1 0}\end{array}$ & $\begin{array}{l}\text { Mild/no ROP } \\
\boldsymbol{n}=\mathbf{3 4 6}\end{array}$ & $p$-Value \\
\hline $\begin{array}{l}\text { Cognitive score, } \\
\text { median (IQR) }\end{array}$ & $85(80-98)$ & $95(85-100)$ & 0.615 \\
\hline $\begin{array}{l}\text { Motor score, } \\
\text { median (IQR) }\end{array}$ & $97(96-105)$ & $100(92-107)$ & 0.963 \\
\hline $\begin{array}{l}\text { Visual } \\
\text { impairment } \\
n(\%)\end{array}$ & $1(16.7)$ & $1(0.6)$ & 0.000 \\
\hline $\begin{array}{l}\text { Cerebral palsy, } \\
n(\%)\end{array}$ & $2(33.3)$ & $22(6.3)$ & 0.055 \\
\hline
\end{tabular}

Abbreviations: IQR, interquartile range; ROP, retinopathy of prematurity.

Note: Some patients had partial follow-up data.

${ }^{a}$ Strabismus, myopia.

Infants with type 1 ROP had worse visual (16.7 vs. $0.6 \%$ ) and neurological development compared with the controls (-Table 2).

A logistic regression analysis was performed including the variables that were significant at univariate analysis to find predictors of laser therapy for type 1 ROP. The model was statistically significant (Hosmer-Lemeshow $=0.816$ ), and the results are presented in - Table 3.

Logistic regression analyses conducted to find out the predictors of neurodevelopmental impairment revealed the following associations: BPD for impaired cognitive development (odds ratio: $2.631,95 \%$ confidence interval $[\mathrm{CI}]: 1.200$ 5.780, $p=0.016$ ), type 1 ROP (odds ratio: $10.417,95 \% \mathrm{CI}$ : 1.149-90.909, $p=0.037$ ), and surfactant administration (odds ratio: $3.952,95 \% \mathrm{CI}$ : $1.102-14.084, p=0.035$ ) for impaired motor development.

\section{Discussion}

This study confirmed that the strongest predictor for type 1 ROP, requiring laser therapy among preterm infants born at a lowincidence setting for ROP, was low GA. The study is in agreement with other reports conducted in high-incidence settings. ${ }^{3,9}$

Table 3 Predictors of laser therapy for type 1 ROP using logistic regression analysis

\begin{tabular}{|l|l|l|l|}
\hline & $\begin{array}{l}\text { Odds } \\
\text { ratio }\end{array}$ & $95 \% \mathrm{Cl}$ & $p$-Value \\
\hline $\begin{array}{l}\text { Increasing gestational } \\
\text { age (d) }\end{array}$ & 0.904 & $0.828-0.986$ & 0.023 \\
\hline $\begin{array}{l}\text { Sepsis } \\
\text { (number of episodes) }\end{array}$ & 1.813 & $0.906-3.629$ & 0.093 \\
\hline $\begin{array}{l}\text { Necrotizing } \\
\text { enterocolitis }\end{array}$ & 2.564 & $0.309-21.292$ & 0.383 \\
\hline Insulin administration & 2.336 & $0.517-10.557$ & 0.270 \\
\hline
\end{tabular}

Abbreviations: $\mathrm{Cl}$, confidence interval; ROP, retinopathy of prematurity.
Other factors, such as insulin requirement, number of late-onset infections, and necrotizing enterocolitis, which were recently reported as potential risk factors, were associated with severe ROP after univariate analysis but were not confirmed after logistic regression analysis. ${ }^{4-7}$

Immature GA might reflect the degree of retinal immaturity at birth and therefore the retinal vulnerability to injury. Furthermore, low GA could increase the duration of an infant's exposure to adverse extrauterine postnatal insults (i.e., oxygen and sepsis) contributing to the risk of ROP.

Severe hyperglycemia requiring insulin therapy has been associated with increased risk of death, sepsis, intraventricular hemorrhage, and ROP. ${ }^{6}$ Hyperglycemia may influence ROP through a reduction of retinal blood flow and an increase in vascular endothelial growth factor (VEGF) production.

Late- but not early-onset sepsis has been associated with severe ROP. The increased risk may be due to systemic and local inflammation with consequent excessive production of VEGF and angiogenesis. ${ }^{7}$

We found an association between severe ROP and necrotizing enterocolitis after univariate analysis. A possible explanation could be that the generalized inflammatory state observed during necrotizing enterocolitis could damage the developing retina due to impaired VEGF production, alterations in local blood flow, and oxidative damage. An alternative explanation of this association could be that necrotizing enterocolitis and ROP represent comorbidities affecting the sickest infants.

Moreover, recent studies reported on the importance of predisposing genetic factors (i.e., polymorphisms of VEGF factor A [VEGFA], endothelial NOS [eNOS]) in the occurrence of ROP and other complications of prematurity. ${ }^{14}$

In a previous study, we showed that the adoption of a controlled oxygen administration policy, with different saturation targets and depending on gestational age, drastically reduced the incidence of severe ROP at our institution. ${ }^{8}$ Thus, the findings of this study come from a low-incidence setting and may not apply to other populations.

The main limitations of this study are the retrospective nature of the analysis and the small number of patients (connected with the low-incidence of ROP at our institution), which may limit the statistical power.

Infants treated for type 1 ROP compared with infants with mild/no ROP had increased visual impairment at 2 years of corrected age; moreover, they tended to show worse neurological development at the same age.

Possible explanations of these findings could be that ROP and brain damage share risk factors; alternatively, some factors associated with severe ROP (i.e., excessive oxygen administration, general anesthesia) may be neurotoxic to the developing brain of very preterm infants.

Predictors of impaired neurodevelopment after logistic regression analysis were type 1 ROP, surfactant administration (for motor development), and bronchopulmonary dysplasia (for cognitive development). The association between BPD and adverse neurodevelopment has been documented ${ }^{15}$ and might depend on the long-term mechanical ventilation of these infants. Surfactant administration was (at the time of the study) performed by tracheal intubation and sedation; we 
speculate that either the procedure itself could be harmful for the developing brain or the need for surfactant may be a proxy for the severity of infants' clinical conditions.

In conclusion, this study showed that low GA was the main factor associated with severe ROP in a low-prevalence setting, and that infants with severe ROP had higher prevalence of visual impairment and worse neurological outcome at 2 years of corrected age. Surfactant administration and BPD were also associated with impaired neurodevelopment. Further studies are warranted to better elucidate the risk factors for severe ROP in other settings.

\section{Conflict of Interest}

None.

\section{References}

1 Mezer E, Chetrit A, Kalter-Leibovici O, Kinori M, Ben-Zion I, Wygnanski-Jaffe $T$. Trends in the incidence and causes of severe visual impairment and blindness in children from Israel. J AAPOS 2015;19(03):260-5.e1

2 Stoll BJ, Hansen NI, Bell EF, et al; Eunice Kennedy Shriver National Institute of Child Health and Human Development Neonatal Research Network. Neonatal outcomes of extremely preterm infants from the NICHD neonatal research network. Pediatrics 2010;126(03):443-456

3 Lundgren P, Kistner A, Andersson EM, et al. Low birth weight is a risk factor for severe retinopathy of prematurity depending on gestational age. PLoS One 2014;9(10):e109460

4 Catenacci M, Miyagi S, Wickremasinghe AC, et al. Dopamineresistant hypotension and severe retinopathy of prematurity. J Pediatr 2013;163(02):400-405
5 Binenbaum G. Algorithms for the prediction of retinopathy of prematurity based on postnatal weight gain. Clin Perinatol 2013; 40(02):261-270

6 Mohamed S, Murray JC, Dagle JM, Colaizy T. Hyperglycemia as a risk factor for the development of retinopathy of prematurity. BMC Pediatr 2013;13:78

7 Tolsma KW, Allred EN, Chen ML, Duker J, Leviton A, Dammann O. Neonatal bacteremia and retinopathy of prematurity: the ELGAN study. Arch Ophthalmol 2011;129(12):1555-1563

8 Nobile S, Gnocchini F, Pantanetti M, Battistini P, Carnielli VP. The importance of oxygen control reaffirmed: experience of ROP reduction at a single tertiary care center. J Pediatr Ophthalmol Strabismus 2014;51(02):112-115

9 Owen LA, Morrison MA, Hoffman RO, Yoder BA, DeAngelis MM. Retinopathy of prematurity: a comprehensive risk analysis for prevention and prediction of disease. PLoS One 2017;12(02): e0171467

10 Axer-Siegel R, Maharshak I, Snir M, et al. Diode laser treatment of retinopathy of prematurity: anatomical and refractive outcomes. Retina 2008;28(06):839-846

11 Gole GA, Ells AL, Katz X, et al; International Committee for the Classification of Retinopathy of Prematurity. The international classification of retinopathy of prematurity revisited. Arch Ophthalmol 2005;123(07):991-999

12 Bayley N. Bayley scales of infant and toddler development. 3rd ed. San Antonio, TX: Pearson; 2006

13 Walsh MC, Wilson-Costello D, Zadell A, Newman N, Fanaroff A. Safety, reliability, and validity of a physiologic definition of bronchopulmonary dysplasia. J Perinatol 2003;23(06):451-456

14 Poggi C, Giusti B, Gozzini E, et al. Genetic contributions to the development of complications in preterm newborns. PLoS One 2015;10(07):e0131741

15 Trittmann JK, Nelin LD, Klebanoff MA. Bronchopulmonary dysplasia and neurodevelopmental outcome in extremely preterm neonates. Eur J Pediatr 2013;172(09):1173-1180 